\begin{abstract}
Iranica
Abstracta Iranica Revue bibliographique pour le domaine irano-aryen

Volume 34-35-36 | 2017

Comptes rendus des publications de 2011-2013
\end{abstract}

\title{
Lloyd Llewellyn Jones. King and Court in Ancient Persia, 559-331 BCE
}

\section{Astrid Nunn}

\section{(2) OpenEdition}

1 Journals

\section{Édition électronique}

URL : http://journals.openedition.org/abstractairanica/41731

DOI : 10.4000/abstractairanica.41731

ISSN : 1961-960X

Éditeur :

CNRS (UMR 7528 Mondes iraniens et indiens), Éditions de l'IFRI

Référence électronique

Astrid Nunn, « Lloyd Llewellyn Jones. King and Court in Ancient Persia, 559-337 BCE », Abstracta Iranica [En ligne], Volume 34-35-36 | 2017, document 101, mis en ligne le 30 décembre 2016, consulté le 03 octobre 2020. URL : http://journals.openedition.org/abstractairanica/41731 ; DOI : https://doi.org/ 10.4000/abstractairanica.41731

Ce document a été généré automatiquement le 3 octobre 2020.

Tous droits réservés 


\title{
Lloyd Llewellyn Jones. King and Court in Ancient Persia, 559-331 BCE
}

\author{
Astrid Nunn
}

\section{RÉFÉRENCE}

Lloyd Llewellyn Jones. King and Court in Ancient Persia, 559-331 BCE. Edingburgh University Press, 2013, XXX-258 p., 3 cartes, 12 fig. (Debates and Documents in Ancient History)

1 L. Llewellyn-Jones analyse la cour achéménide sous un aspect politique et social. Dans un premier chapitre l'A. s'attache au « Grand Roi et ses hommes » (p. 12-41). Le second chapitre est dédié aux institutions ("Pomp and Circumstance: Monarchy on Display", p. 42-73) et le troisième à l'apanage du roi en route ("The Great King in His Empire: The Movable Court", p. 74-95). Les deux derniers chapitres sont sociaux-culturels et traitent du harem et des femmes (p. 96-122) ainsi que des plaisirs et des risques de la vie aulique (p. 123-150). Comme déjà pour le « harem » des rois médio-assyriens l'A. s'interroge sur le bien-fondé de l'usage de ce terme qu'il défend.

2 Ce texte ayant paru dans la collection " Debates and Documents in Ancient History ", 132 documents originaux suivent (p. 151-228). Ces documents consistent surtout en extraits de textes classiques et concernent les thèmes abordés dans le texte principal. Les photos illustrent les monuments achéménides les plus célèbres. Cette étude est nettement plus orientée sur l'histoire (classique) et l'histoire sociale, où le harem royal et les femmes jouent un rôle particulièrement important. Elle offrira une bonne introduction pour ces domaines. 


\section{AUTEURS}

\section{ASTRID NUNN}

Université de Munich 